\title{
Application of TOPSIS Method in Solving Location Problems, the Case of Western Serbia
}

\author{
Vojislav Tomić ${ }^{1}$, Zoran Marinković ${ }^{1}$, Danijel Marković ${ }^{1}$ \\ ${ }^{1}$ Faculty of Mechanical Engineering/department for transport technology and logistics, University of Nis, Niš (Serbia)
}

The topic of this paper are Logistic Centers, main points of transport networks and finding optimal locations for their locations in the area of Western Serbia. Republic of Serbia can plan development of logistics in accordance with principles applied to successful countries in world. With the globalization growth of Logistic Centers, Republic of Serbia which connects eastern and western trades can become the new potential places of foreign investments. According to that, the aim of this paper is to propose concrete steps that will enable better logistic support with making decisions about new Logistic Center locations in the area of Western Serbia. The first part of the paper shows basic notes about logistic centers, i.e. their sorts, functions and characteristics have been analyzed. Further in the paper, special attention is dedicated to the development of such a logistic center in the area of Western Serbia on the future highway E-761. Numerical example is further used to illustrate the application of TOPSIS method for the selection of the most suitable logistic center locations. By using TOPSIS method on location problems, it is demonstrated that the algorithm is simple and practicable for fast decisions.

Keywords: location problems, logistic centres, transport networks, TOPSIS method.

\section{INTRODUCTION}

Warehouse facilities appeared in the distant past, practically from the moment when the man reached the stage of development in which he could grown and obtain enough food in the summer to provide nutrition during the winter. Today, warehouse is defined as facilities, containing resources (equipment, people...) and other elements of the system that are technologically organized and used in a warehouse of goods [1]. The biggest step forward in the construction of warehouses technology is reached during the Industrial Revolution. [2]

Transport of goods reaches an impressive growth in recent years and this trend in the distribution of goods is still present. Distribution of goods is supported significantly by the sustainable grow of a global integrated logistics networks [3], and the rapid progress of ecommerce [4] while logistics centers (LC) represent a link in the distribution process between macro and micro distribution.

Serbian integration into the modern logistic flows of the European supply chains represents one of the basic infrastructural objectives of the state. Guided by this vision, the aim of this paper is to promote the development of new LC. Special attention in the paper is dedicated to the development of such an LC in the Western part of Serbia and its importance to the economic development of the city, region and state.

In this paper, a analysis of the curent LC location situation in the Republic of Serbia were made. On the basis of this analysis, application of appropriate mathematical models has been used in order to optimize the current location system of LC. Optimization recommendations are related to the easer decision-making procedure for the optimal location of the LC. The aim of the paper is to evaluate three potential sites (alternative) in the area of western Serbia in relation to five different criteria. As a final result obtained in this paper is the optimal location solution of the LC in the Western Serbia.

\section{LITERATURE REVIEW}

The theory of location problem deals with the task of choice of one or more locations for facilities that provide services in the area of certain dimensionality. During the location selection, the interactions among locations themselves and users must take into account. The importance of location problems confirms the fact that the first written note of the location problems was found in the Bible. The first step, from the mathematical point of view, to solve these problems was made by the French mathematician Pierre de Fermat. Beside Pierre de Fermat, the first who pointed out the practical importance of location problems in the literature was Alfred Weber. In his book [5], using one of the first location problems in the history of mathematics, he has presented the problem of minimizing transportation costs in the industry. Furthermore, in the more contemporary literature O'Kelly gave a first formulation of a complex location model where the LC may be located anywhere in the area so that the sum of squares of distances is minimum [6]. In addition to continuous location problems in the area, there are allso continuous location problems on a sphere in which the applications are separately distributed [7].

In the literature, for solving locations problems, methods of multi-criteria decision making are frequently used [8] [9]. In this case, decisions are usually made in the evaluation of set possible solutions (alternatives) with respect to a given set of criteria. According to the character of the solutions multi-criteria methods are generally divided into hard and soft methods of optimization: the first give optimal, and the second compromised (best) solution. For this purpose, the methods of analysis have been developed, among which: Preference ranking Organization Method for Enrichment Evaluations (PROMETHHE) [10], Electra [11], the Analytic Hierarchy Process (AHP) [12] and The Technique for Order of Preference by Similarity to Ideal Solution (TOPSIS) [13]. 
All the above mentioned methods are the methods of soft optimization because there use heuristic parameters, measurements of distance and scale of values [14].

This paper illustrated the real case of applying one of the modern methods of multi-criteria decision making. TOPSIS method is used in decision-making and evaluation of the most appropriate LC location of Western Serbia.

\section{LOGISTIC CENTERS}

LC represents an entire warehouse places built on a road or rail hubs, next to ports or airports. Through them, all commodity flows are performed, from transport and storage, to order, packaging and supplies management.

LC is usually located near major cities where there is a need for large amounts of goods to be distributed from one city to small urban systems, and from that place to further distribute them in regional centers.

The importance of LC in Europe began to develop in the 70s of the last century, mainly on the basis of partial private and social initiatives of the companies in the field of transport, logistics and urban and regional authorities, chambers of commerce, etc.. During the 90s, the concept of large LC becomes the subject of plans and projects of the leading developed European countries [15,16].

In order to illustrate the importance of LC the best, Figure 1 shows the traditional and modern way of distribution, or distribution method with and without LC. According to these solutions there are two main distribution systems which are implemented in logistics: direct delivery, Figure 1a, and indirect delivery via a logistics center (LC), Figure $1 b$.

Traditional delivery of goods (Fig. 1a) supplier to users without any intermediaries is the simplest, but for industrial consumer goods it is unprofitable for both suppliers and users. The user is deprived of choosing the same goods from different manufacturers, as well as the ability to simultaneously obtain more different products in adequate quantities. Therefore, in such cases, LC is included, which collects the goods from different suppliers and then distribute them to the users (Fig. 1b). Because of that, between the supplier and the user a centralized distribution system has been introduced - LC, in which suppliers bring homogeneous goods in large quantities, and then forming new, usually inhomogeneous shipments of goods to the desired (ordered) the quantities delivered to customers. Centralized distribution of goods in terms of transport and planning tours and routes is much better than in the first system.

In the world and Europe LC is a term that is most accepted, but the existing linguistic at the national level influence that LC in European countries earned various other names including: England: Freight Villages (FV), France Plate

Serbia is a European country that occupies the central part of the Balkan Peninsula. It covers an area of $88,361 \mathrm{~km}^{2}$ and has about 7,397,651 residents. An important geographical position makes Serbia a crossroads linking the central and northern Europe to Greece and Asia Minor. The logistics market in Serbia is currently quite underdeveloped [15] and has only a few objects that are in some way involved in logistics activities. It mainly refers to the free zone and distribution warehouses which are located around major transport nodes and corridors in the country.

\section{MATHEMATICAL DESCRIPTION OF THE} PROBLEM

In this paper, to determine the most appropriate location LC in the territory of western Serbia, a method Technique for Order Preference by Similarity to Ideal Solution (TOPSIS) has been used. TOPSIS method is based on the concept that the chosen alternative should have the shortest distance from the ideal solution and the longest of the anti-ideal solution [17]. The criteria can be represented in a multi-dimensional coordinate system, where each criterion corresponds to a coordinate axis. TOPSIS method ranks the alternatives from the so-called ideal solution and negative ideal solution, which must be determined first. The ideal solution minimizes the cost criteria, and the criteria maximize profits. Minimum ideal solution applies inversely. The optimum alternative is geometrically closest to the ideal solution.

A method of calculating TOPSIS method comprises 6 steps as follows [18]:

Step 1: The normalization of decision matrix;

Step 2: Multiplying the normalized matrix by weight coefficients;

Step 3: Determination of ideal solutions;

Step 4: Determination of the alternative distance from the ideal solutions;

Step 5: Determining the relative closeness of alternatives to the ideal solution.

Step 6: Ranking the alternatives.

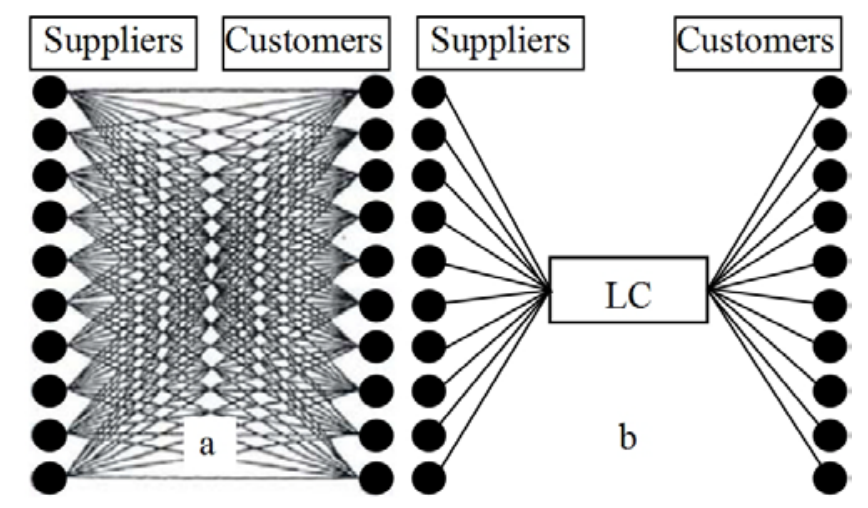

Figure 1: Direction of distribution: a) the direct delivery, b) indirect delivery - LC 


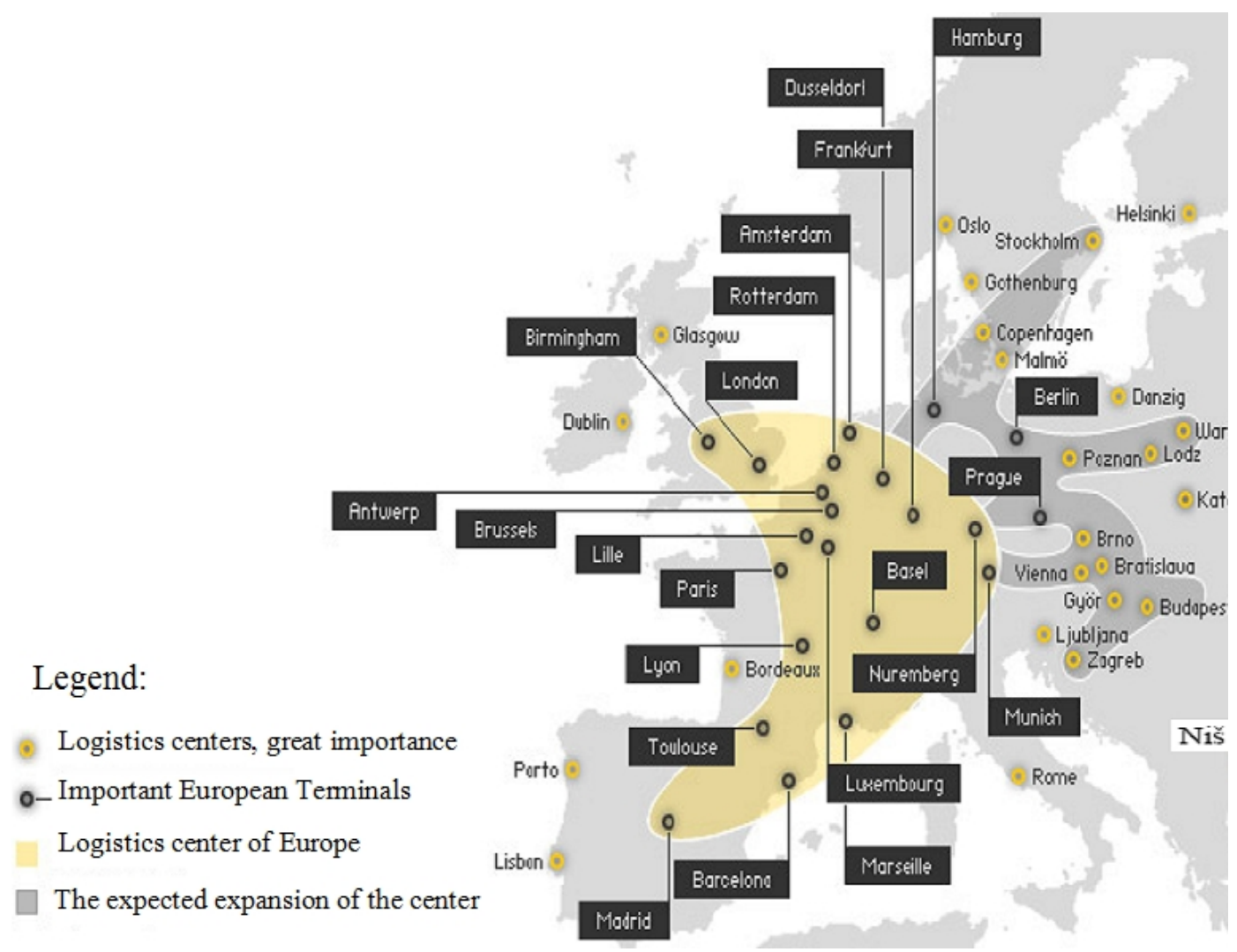

Figure 2 Map of logistics centers in Europe

In order to obtain an optimal solution, TOPSIS method starts by making the first step in normalizing payoff matrix:

Step 1: Normalizing payoff matrix:

In the payoff matrix (1), in general, a number of values have different metric. Therefore, the first normalization of the elements is performed according to the relation (2), in order to obtain the matrix (3), in which all the elements are dimensionless

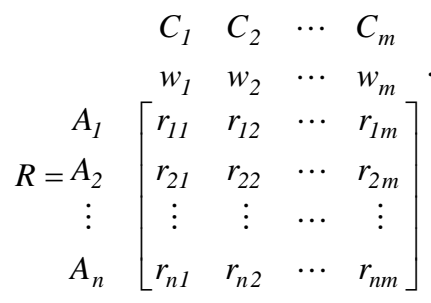

$$
\begin{aligned}
& x_{i j}=\frac{r_{i j}}{\left[\sqrt{\sum_{i=1}^{n} r_{i j}^{2}}\right]} . \\
& \begin{array}{llll}
C_{1} & C_{2} & \cdots & C_{m}
\end{array} \\
& \begin{array}{llll}
w_{1} & w_{2} & \cdots & w_{m}
\end{array} \\
& x=\begin{array}{c}
A_{1} \\
A_{2} \\
\vdots \\
A_{n}
\end{array}\left[\begin{array}{cccc}
x_{11} & x_{12} & \cdots & x_{1 m} \\
x_{21} & x_{22} & \cdots & x_{2 m} \\
\vdots & \vdots & \cdots & \vdots \\
x_{n 1} & x_{n 2} & \cdots & x_{n m}
\end{array}\right]
\end{aligned}
$$

After that, normalized matrix is multiplied by the weight coefficients of criteria, which represents the second step in getting the ideal solution:

Step 2: Multiplying the normalized payoff matrix by weight coefficients of criteria. Using the relation (4) weight normalized performance matrix is determined $V=$ $\left(V_{i j}\right)$, where each $V_{i j}$ is the product of normalized performance alternative and appropriate weighting coefficient criteria.

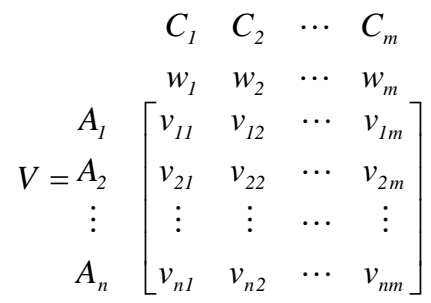

$$
\begin{aligned}
& \begin{array}{c}
C_{1} \\
A_{1} \\
A_{2} \\
\vdots \\
A_{n}
\end{array} \quad\left[\begin{array}{ccll}
w_{1} v_{11} & w_{2} v_{12} & \cdots & c_{m} \\
w_{1} v_{21} & w_{2} v_{22} & \cdots & w_{m} v_{2 m} \\
\vdots & \vdots & \cdots & \vdots \\
w_{1} v_{n 1} & w_{2} v_{n 2} & \cdots & w_{m} v_{n m}
\end{array}\right]
\end{aligned}
$$

Step 3: Determination of ideal solutions. In order to determine the ideal solution, an ideal solution $\left(\mathrm{A}^{*}\right)$ and the negative ideal solution $\left(\mathrm{A}^{-}\right)$is determined by using the relation (5) and (6). 


$$
\begin{gathered}
A^{*}=\left\{\left(\max v_{i j} \vdots j \in G\right),\left(\min v_{i j} \vdots j \in G^{\prime}\right), i=1 \ldots n\right\}\left\{v_{1}^{*}, v_{2}^{*}, \ldots . . v_{m}^{*}\right\}, \\
\cdot \\
A^{-}=\left\{\left(\min v_{i j} \vdots j \in G\right),\left(\max v_{i j} \vdots j \in G^{\prime}\right), i=1 \ldots n\right\}\left\{v_{1}^{*}, v_{2}^{*}, \ldots . v_{m}^{*}\right\},
\end{gathered}
$$

where:

$$
\begin{aligned}
& G=\left\{j: C_{j} \text { je maksimiziran kriterijum, } j=1,2 \ldots m\right\} . \\
& G^{\prime}=\left\{j \vdots C_{j} \text { je minimiziran kriterijum, } j=1,2 \ldots m\right\} .
\end{aligned}
$$

The best alternatives are with the maximum $v_{i j}$ in relation to the maximized criteria and minimum $v_{i j}$ minimized criteria $A^{*}$ indicates the best alternative - the ideal solution, and by the same logic $A^{-}$indicates the negative ideal solution [14].

Step 4: Determining the alternative distance from the ideal solutions. Further using the relation (7) and (8) can determine the distance of an alternative to the ideal solution. In this step, n-dimensional Euclidean distances of all the alternatives are calculated, from the ideal to the negative ideal solution.

$$
\begin{aligned}
& S_{i}^{*}=\sqrt{\sum_{j=1}^{m}\left(v_{i j}, v_{j}^{*}\right)^{2}, .} \\
& S_{i}^{-}=\sqrt{\sum_{j=1}^{m}\left(v_{i j}, v_{j}^{-}\right)^{2}}, .
\end{aligned}
$$

Step 5. Determining the relative closeness of alternatives to the ideal solution. For each alternative the relative distance from the ideal solution to the equation has been determined (9):

$$
Q_{i}^{*}=\frac{S_{i}^{-}}{S_{i}^{*}+S_{i}^{-}}, i=1, \ldots, n
$$

where:

$0 \leq Q_{i}^{*} \leq 1$. Alternative $A_{i}$ is closer to ideal solution if the value $Q_{i}^{*}$ is closer to 1 , which is the same $S_{i}^{*}$, if it is closer to 0 value.

Step 6. Ranking the alternatives. Alternatives are ranked by decreasing values $Q_{i}^{*}$. TOPSIS method ranks the alternatives according to closeness to the certain ideal values of criteria. The alternative with the least distance from the ideal solution in the set of possible solutions is defined as the best. Distance measuring (10) is the family $L_{p}$ - the metric given as:

$$
L_{p}(i)=\left[\sum_{j=1}^{m} w_{j}^{p}\left(\frac{r_{j}^{*}-r_{i j}}{r_{j}^{*}-r_{j}^{* *}}\right)^{p}\right]^{1 / p}
$$

Where:

$L_{p}(i)$ stands for $L_{p}$-alternative metrics $A_{i}, r_{i j}$ ranking alternatives $A_{i}$ in relation to criterion $C_{j}, r_{j}^{*}$ and $r_{j}^{* *}$ and it is the best and worst rating value in a set of alternatives for criterion $C_{j}, p$ parameter preferences of decision makers in the evaluation. As before, $m$ denotes a number of criteria, and $n$ the number of alternatives. An alternative with the minimum $L_{p}$ - metric is considered to be the best, and the ranking is done by growing $L_{p}-$ metric. The weighting coefficient of criteria $w_{j}(j=1,2, \ldots m)$ are the normalized values of the original marks, which is defined by a decision maker or group of decision makers (as in this paper case), so that their sum is 1 . Parameter $p$ indirectly expresses preferences of balancing criteria $(p=1)$, by the normal use of the effect of squaring the errors $(p=2)$, or the search for the absolutely dominant solution $(p=\infty)$.

If we allow mutual criteria compensation, $p$ must be 1 , upon reduce of the marginal value of the target function, $p$ must be greater than 1 , as only the absolute best alternative is important, $P$ must be infinite. In each of these cases, the objective function of the optimization problem is transformed into a different shape.

\section{METHODOLOGY IMPLEMENTATION ON A REAL PROBLEM}

In applying this method, it is first necessary to determine possible alternative solutions and accept the necessary criteria to evaluate given alternatives. Potential locations (alternative) of Regional LC have been accepted:

A) City of Novi Pazar,

B) City of Čačak and

C) City of Kraljevo.

Alternatives are regional centers for the eponymous districts: Novi Pazar, Cacanski and Kraljevski (Figure 3). The density of population by districts, in which the cities are located, is about 100 inhabitants per $\mathrm{km}^{2}$ with the highest population density in Cacanski district with about 150 inhabitants per $\mathrm{km}^{2}$ while the lowest density is in the Kraljevo district, about 80 inhabitants per $\mathrm{km}^{2}$. After defining the alternatives, the next is defining the criteria by which the alternatives will be evaluated. Upon criteria selection, leading experts in the world of logistics in the mentioned areas have been consulted.

Based on the above mentioned, five criteria have been selected in this paper:

As the $1^{\text {nd }}$ criteria, LC usable area in square meters and the construction cost of one square meter in euros is taken, which indexed by alternatives is:

$\mathrm{A}=205$,

$\mathrm{B}=178$,

$\mathrm{C}=205$.

As the $2^{\text {nd }}$ criterion, total cumulative length of all manipulative and connecting tracks, i.e. internal roads, is taken, and per the alternatives it is [19]:

$\mathrm{A}=2090$,

$\mathrm{B}=1370$,

$\mathrm{C}=600$. 


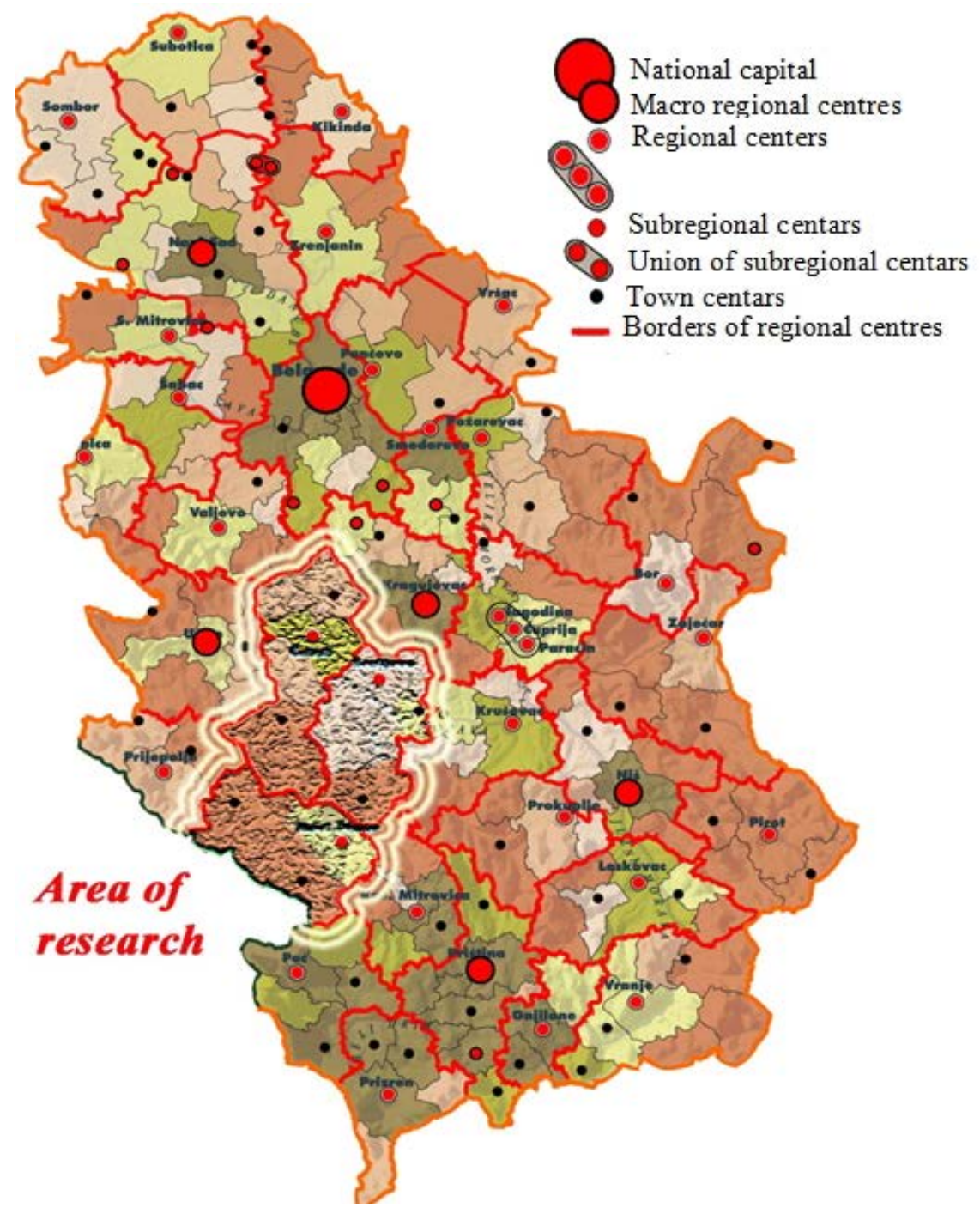

Figure 3. Map of regional centers in Serbia with their districts

As the 3rd criterion, the manipulative space is not taken because it is the same for each alternative. Data length of the present accessible road has already been used, and local roads in meters are:

$\mathrm{A}=1730$,

$\mathrm{B}=3250$,

$\mathrm{C}=24600$.

As the $4^{\text {th }}$ criterion, total surface of parking lots and garages in square meters is taken, and by the alternatives it is:

$\mathrm{A}=8140$,

$\mathrm{B}=3250$,

$\mathrm{C}=8440$.

As the 5th criterion, subjective assessment of individual alternatives is taken, relying on the following data: the number of manipulative tracks, access to the facility, the possibility of extension, the need for demolition of the existing facilities, a possible explosion of land and relocation of roads. According to this criterion, the values of alternatives are marked 1-9: $\mathrm{A}=4$,
$\mathrm{B}=2$,

$\mathrm{C}=9$.

Based on the given alternatives and adopted criteria Table 1 has been created. Input data are given as the euros, meters, square meters, kilometers and one is nondimensional (subjective assessment). To get in a position to compare these data, it is necessary to preserve the normalized matrix, so that existing matrix becomes nondimensional, and at the same time, its value ranges from 0 to 1 .

In order to reach these relationships the formula is used (1), and the results are shown in the Table 2. As for decision-making not all criteria are equally important, for additional information about inter-criteria references weighting coefficients for each criterion separately have been introduced (Table. 3). Multiplying the normalized matrix by weight coefficient of criteria using the relation (4), weight normalized performance matrix has been determined $V=\left(v_{i j}\right)$, where each $v_{i j}$ is the product of the normalized alternative performance and appropriate weighting coefficient criteria (Table 4). 
Table 1. Relation of alternatives and criteria for selection of the optimal location solution

\begin{tabular}{|c|c|c|c|}
\hline Alternatives & A & B & C \\
\hline 1. & 205 & 178 & 205 \\
\hline 2. & 2090 & 1370 & 600 \\
\hline 3. & 1730 & 3250 & 2460 \\
\hline 4. & 8140 & 7940 & 8440 \\
\hline 5. & 4 & 2 & 9 \\
\hline
\end{tabular}

Table 2 Normalized values

\begin{tabular}{|c|c|c|c|c|c|}
\hline & 1 & 2 & 3 & 4 & 5 \\
\hline A & 0.602 & 0.813 & 0.390 & 0.374 & 0.398 \\
\hline B & 0.523 & 0.533 & 0.733 & 0.560 & 0.199 \\
\hline C & 0.602 & 0.233 & 0.555 & 0.595 & 0.395 \\
\hline
\end{tabular}

Table 3 The weight coefficients of criteria

\begin{tabular}{|c|c|c|c|c|c|}
\hline Criteria & 1 & 2 & 3 & 4 & 5 \\
\hline Weight coefficients & 0.3 & 0.1 & 0.1 & 0.2 & 0.1 \\
\hline
\end{tabular}

Table 4. The weighted normalized matrix performance

\begin{tabular}{|c|c|c|c|c|}
\hline 1 & 2 & 3 & 4 & 5 \\
\hline $\min$ & mah & mah & mah & mah \\
\hline 0.1569 & 0.0813 & 0.0733 & 0.1190 & 0.0895 \\
\hline
\end{tabular}

After getting the weighted normalized performance matrix, the process of seeking a variation which is the nearest to the ideal and farthest from the antiideal point is presented by formula (7), (8): coordinates:

The ideal point is a vector with the following (0.1569, 0.0813, 0.0733, 0.1190, 0.0895)

while anti-idela point is the vector with the following coordinates:

, (0.1806, 0.0233, 0.0390, 0.1120, 0.0398)

Acordian to that:

Alternative A distance from the ideal point:

$0.0775=C_{1}^{+}$,

Alternative B distance from the ideal point:

$0.0753989=C_{2}^{+}$,

Alternative $\mathrm{C}$ distance from the ideal point:

$0.0651347=C_{3}^{+}$(Figure. $4 a$ ).

While the distance between the points of the ideal anti-points as follows:

Alternative A distance from the anti-ideal point: $0.0580675=C_{1}^{-}$,

Alternative $\mathrm{B}$ distance from the anti-ideal point: $0.0667724=C_{2}^{-}$,

Alternative $\mathrm{C}$ distance from the anti ideal point:

$0.0676178=C_{3}^{-}($Figure $4 b)$.

Comparison of the alternative distance from the ideal, i.e. anti ideal point is shown in Figure 4c.
Finally, we calculate the relative closeness which represents the ideal compromise between proximity and further anti-ideal points for each alternative separately. Using formula (9):

The relative closeness of alternatives $A=0.428329$,

The relative closeness of alternative $B=0.4731877$

and the relative closeness of alternative $C=0.5093523$.

On the basis of mathematical model and its application to the illustrated model LC in western Serbia, following results were obtained:

It is calculated that the best location to build a new LC is the alternative C, i.e. the city of Kraljevo, as the second alternative the city of Cacak and the last Novi Pazar.

1 C: location LC Kraljevo

2 B: location LC Cacak

3 A: location LC Novi Pazar.

\section{CONCLUSION}

Logistics centers in Europe stand for the concept that has seriously been considered in the last twenty years. The mathematical method, which is applied in this paper, provides the basis for evaluating the location efficiency of the most suitable location in the LC of Western Serbia.

Based on the above mentioned, we can conclude:

1. A number of different concepts of LC start the dilemma of the common characteristics of the systems they describe. LC does not use one term, the term depending on language areas (England: Freight Villages, France: Plate Forme Logistique and Plat Form multimodales, Germany: Giiterverkehrszentrum, Italy Interporto, Spain: Centro de integrado mercancías, Denmark: Transport Centre etc.).

2. Deciding on the location of the LC, is among the location problems that are characterized by multi-criteria decision making in planning.

3. TOPSIS method, which is one of the methods of soft optimization, is widely applied method in solving location problems. 


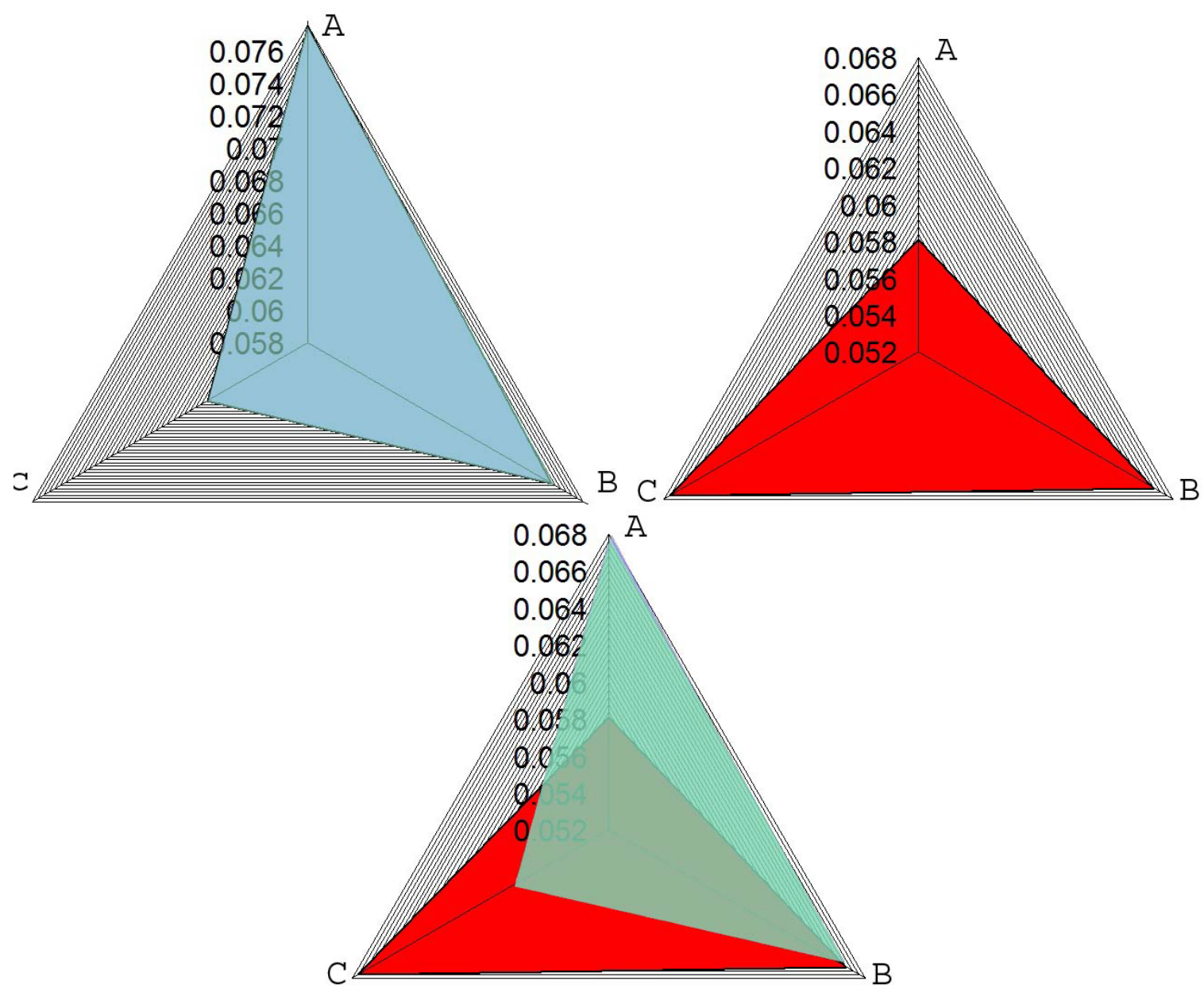

Figure 4. Results of TOPSIS methods

4. Numerical examples are used to illustrate the application of TOPSIS method in selecting the most appropriate location LC that would be found on the territory of Western Serbia.

5. Based on 5 criteria, three potential sites have been evaluated (alternatives), and as a result, the city of Kraljevo is rated as the best location.

6. By applying TOPSIS method it is proved that the algorithm is simple, feasible and affordable in making quick decisions.

7. Logistics Development Strategy of the Republic of Serbia should be based on the following principles:

- Integration of LC in strategy development

- Investing in the reconstruction of transport infrastructure,

- Stimulus and additional subsidies to companies that want to invest in the development of LC in Serbia.

- To provide marketing and business integration through the European co-operation with other major LC in the world (eg, the U.S., Russia, Japan, China, India, Brazil).

\section{REFERENCES}

[1] S. Vukićević, „Skladišta“, Preving, Beograd (1995).

[2] S. Zečević, „Robni terminali i transportni centri“, Saobraćajni fakultet univerziteta u Beogradu, Beograd, (2006).
[3] A. Zhang, „Analysis of an international air cargo hub: the case of Hong Kong“, Journal of Air Transport Management 9 (2), 123-138, (2003).

[4] A. Zhang, and Y. Zhang, "Issue on liberation of air cargo services in international aviation”, Journal of Air Transport Management 8 (5), 275-287, (2002).

[5] A. Weber, "Über den Standort der Industrien", Tübingen (1909) (English translation by Friedrrich C.J., Theory of the Location of Industries, University of Chicago Press), (1909).

[6] M. O'Kelly, "A quadratic integer program for the location of interacting hub facilities“, European Journal of Operational Research 32, 393-404, (1987).

[7] T. Aykin and G.F. Brown, "Interacting new facilities and location-allocation problems“, Transformation Science, 26, 221-222, (1992).

[8] J. Current and H. Min, D. Schilling, "Multi objective analysis of facility location decisions", European Journal of Operational Research, Vol. 49, No 3, 295307 (1990)

[9] M. Aruldoss, T. M. Lakshmi and V. P Venkatesan, "A survey on multi criteria decision making methods and its applications”, American Journal of Information Systems, Vol. 1, 31-43, (2013). 
[10] J.P. Brans, P. Vincke and B. Mareschal, "How to select and how to rank projects: the PROMETHEE method", European Journal of Operational Research / EJOR, 24, 2, 228-238, (1986).

[11] B. Roy, "Classement et choix en presence de points devue multiples, la methode ELECTRE”. Revue d Informatique et de recherche operationelle, 6(8) 5775, (1968).

[12] T.L. Saaty, "The analytic hierarchy process", New York, itd: McGraw-Hill, (1980).

[13] C.L. Hwang and K.S. Yoon "Multiple attribute decision making”, Methods and applications. New York: Springer, (1981).

[14] B. Srdjevic, Z. Srdjevic and T. Zoranovic, "PROMETHEE, TOPSIS i CP u visekriterijumskom odlucivanju u poljoprivredi”, Letopis naucnih radova 26 (1), 5-23, (2002).
[15] V. Tomić and M. Jovanović, "Uporedna analiza metoda pri izboru lokacije logističkog cargo centra", slučaj Srbija, IMK-14 Istraživanja i razvoj, No 35/2/10, 49- 54, (2010).

[16] C. Lippolt, prevod knjige: "Sistemi skladištenja i distribucije", Katedra za transportnu tehniku i logistiku, Mašinski fakultet Univerziteta u Nišu, Niš, (2005)

[17] T.C. Chu, "Facility location selection using fuzzy TOPSIS under group decisions”, International Journal of Uncertainty, Fuzziness and Knowledge-Based Systems Vol. 10 (6), 687-701, (2002).

[18] B, Blagojević, M. Matić-Kekić, D. Ružić and D. Dedović, "Application of saw, topsis and cp methods in the tractors ranking based on the ergonomic characteristics" Savremena poljoprivredna tehnika, Vol. 38, No. 4, 287-376, (2012).

[19] V. Đorđević, Robno transportni centri, master rad, Mašinski fakultet Kraljevo, Univerzitet u Kragujevcu, (2010). 